Check for updates

Cite this: RSC Adv., 2019, 9, 15257

\title{
Synthesis of mesoporous lanthanum hydroxide with enhanced adsorption performance for phosphate removal $\uparrow$
}

\author{
Kyungmin Kim, \$ Dujin Kim, \$Taeyeon Kim, (D) Bong-Geun Kim, Donghyun Ko, \\ Junsoo Lee, Yujin Han, Ji Chul Jung and Hyon Bin Na (iD*
}

\begin{abstract}
Phosphate is a ubiquitous pollutant in aquatic systems, and increasingly stringent post-treatment phosphate effluent standards necessitate increasingly efficient removal techniques. In this study, mesoporous lanthanum hydroxide (MLHO) was synthesized by a hard-template method using ordered mesoporous silica, and its potential as an adsorbent for high-efficiency phosphate removal in aqueous solutions was tested. The porosity characteristics of MLHOs were controlled by adjusting the template structure and synthesis conditions. MLHO adsorbents showed great potential for phosphate removal from solutions containing both high and low initial phosphate concentrations. The phosphate adsorption capacity of MLHO strongly depended on its surface area as this process was governed by monolayer adsorption. Moreover, the phosphate removal performance of MLHO was affected by its structural properties. MLHO showed a high adsorption capacity of $109.41 \mathrm{mg} \mathrm{P} \mathrm{g}^{-1}$ at $28{ }^{\circ} \mathrm{C}\left(q_{\mathrm{m}}\right.$ by the Langmuir isotherm model). Further, it showed ultrafast adsorption in a solution with low initial concentration of $2 \mathrm{mg} \mathrm{P} / \mathrm{L}$; within the first $10 \mathrm{~min}, 99.8 \%$ of phosphate was removed, and the phosphorus concentration remaining in the solution dramatically reduced to $4 \mu \mathrm{g} \mathrm{P} / \mathrm{L}$. These findings suggest that MLHO adsorbent is a good candidate for rapid and efficient low-concentration phosphate removal to meet the increasingly stringent discharge standards for wastewater treatment plants.
\end{abstract}

Received 1st February 2019

Accepted 29th April 2019

DOI: $10.1039 / \mathrm{c} 9 \mathrm{ra00895k}$

rsc.li/rsc-advances classified into chemical precipitation, biological treatment, ion exchange, and adsorption. ${ }^{3}$ Although biological processes are widely used in wastewater treatment plants (WWTPs), they are recommended for treating wastewater with only moderate $\mathrm{P}$ concentrations of $0.3-2 \mathrm{mg} \mathrm{L}{ }^{-1}{ }^{4}$ Their efficacy for treating effluents containing low phosphate concentrations remains debatable. ${ }^{5,6}$ Adsorption is a simple and economical process for high-efficiency phosphate removal even at low P concentrations, and it is considered eco-friendly given the relatively low production of sludge. ${ }^{7,8}$

Among metal-based adsorbents, lanthanum (La)-based materials are promising for phosphate removal because of their chemical stability and strong affinity for phosphate. ${ }^{9}$ Ladoped or -modified adsorbents show advantageous features including high adsorption capacity and wide operating $\mathrm{pH}$ range compared to both host materials and La alone. In particular, recent advances in materials synthesis have enabled the engineering of their properties and functionality via the formation of nanostructures. ${ }^{10}$ These adsorbents have attracted research attention because of their large surface-area-to-volume ratio and related high reactivity and capacity. Mesoporous silicas, including MCM-41, MCM-48, and SBA-15, have been widely reported as host materials for phosphate adsorption. Although mesoporous silicas themselves remove minimal phosphate from water, they show good phosphate adsorption
Department of Chemical Engineering, Myongji University, Yongin, Gyeonggi-do 17058, Republic of Korea. E-mail: hyonbin@mju.ac.kr

$\dagger$ Electronic supplementary information (ESI) available. See DOI: 10.1039/c9ra00895k

\$ These authors (K. Kim, D. Kim) have contributed equally to this work. 
ability when La is incorporated into them. ${ }^{\mathbf{1 1}}$ For instance, Huang et al. reported La-doped mesoporous silica spheres that showed high adsorption capacity (42.76 $\mathrm{mg} \mathrm{P} \mathrm{g}^{-1}$ ) owing to efficient phosphate transport originating from their small overall size of $300 \mathrm{~nm} .{ }^{\mathbf{1 2}}$ Various other functional materials, including zeolites, ${ }^{13}$ cellulose fibers ${ }^{14}$ polymers,${ }^{15}$ hydrogels, ${ }^{16}$ clays, ${ }^{17}$ and carbons, ${ }^{18}$ can also serve as host materials for loading La-based adsorbents.

Owing to rising concerns over eutrophication, many countries are expected to set increasingly stringent $\mathrm{P}$ discharge standards for WWTPs of $0.1 \mathrm{mg} \mathrm{L}{ }^{-1}$, or even less. ${ }^{19}$ Therefore, it is essential to achieve satisfactory $\mathrm{P}$ removal to meet the strict standards for secondary effluents from WWTPs. Accordingly, several recent studies have focused on phosphate removal at low $\mathrm{P}$ concentrations of $<10 \mathrm{mg} \mathrm{P} / \mathrm{L}$, which is in the range of $\mathrm{P}$ concentrations in WWTPs treating domestic wastewater. ${ }^{\mathbf{1 1 , 1 5 , 2 0 , 2 1}}$ They suggested that the pore structure of host materials and La dispersity on them determine efficient contact and reaction with phosphate, in turn influencing fast and complete removal of phosphate at low $\mathrm{P}$ concentrations. Thus, the new adsorbent should be developed considering both chemical and morphological design for phosphate removal in practice.

Recently, lanthanum oxide $\left(\mathrm{La}_{2} \mathrm{O}_{3}\right)$ and lanthanum hydroxide $\left(\mathrm{La}(\mathrm{OH})_{3}\right)$ in micro- and nanostructures without any host material were synthesized and applied for phosphate removal. ${ }^{20,22}$ Compared to La-doped or -incorporated materials, they were expected to have higher adsorption capacities owing to their high La content and rigid structure. Variously shaped $\mathrm{La}_{2} \mathrm{O}_{3}$ microparticles were reported to show shape-dependent phosphate removal efficiency. ${ }^{22}$ Hierarchical $\mathrm{La}_{2} \mathrm{O}_{3}$ particles with larger surface areas showed better phosphate removal ability than other microparticles. However, there are obvious structural limits to controlling the pore structure and increasing the surface area of $\mathrm{La}_{2} \mathrm{O}_{3}$ particles. Mesoporous materials have much larger surface area than nanoparticles, and the functionalities originating from their unique structures have been applied in various fields including environmental, energy, and biomedical fields. ${ }^{23-25}$ In particular, mesoporous transition metal oxides with controlled morphologies have attracted much research attention owing to their large surface area and surface-originating activity as catalysts and adsorbents. ${ }^{26,27}$ Mesoporous materials comprising $\mathrm{La}_{2} \mathrm{O}_{3}$ or $\mathrm{La}(\mathrm{OH})_{3}$ are expected to have high adsorption capacities owing to their large surface area and the designed structure of nanopores and channels. However, to the best of our knowledge, mesoporous materials of $\mathrm{La}_{2} \mathrm{O}_{3} / \mathrm{La}(\mathrm{OH})_{3}$ have never been reported as phosphate adsorbents unlike other metal oxides.

This paper reports the synthesis of mesoporous lanthanum hydroxides (MLHOs) by a hard-template method using ordered mesoporous silica. The pore structure of the resulting $\mathrm{La}(\mathrm{OH})_{3}$ was controlled based on the template and reaction conditions used for synthesis. The resulting material was investigated as a phosphate adsorbent with a large surface area and wellorganized pores. Its phosphate adsorption capacity was analysed, and its phosphate removal efficiency under lowphosphate concentrations was further evaluated to assess the potential in practical applications.

\section{Experimental}

\section{Synthesis of ordered mesoporous silica}

Pluronic P123 (MW: 5800, $\mathrm{EO}_{20} \mathrm{PO}_{70} \mathrm{EO}_{20}$ ), tetraethoxysilane (TEOS), lanthanum nitrate hexahydrate $\left(\mathrm{La}\left(\mathrm{NO}_{3}\right)_{3} \cdot 6 \mathrm{H}_{2} \mathrm{O}\right)$, and citric acid were purchased from Sigma-Aldrich (St. Louis, MO, USA). Hydrochloric acid, sodium hydroxide, and ethanol were obtained from Samchun Chemicals (Seoul, South Korea). 1Butanol was purchased from Junsei Chemicals (Tokyo, Japan).

Ordered mesoporous silica (KIT-6) was used as a template to prepare MLHO. Two sets of KIT- 6 were prepared at two different hydrothermal temperature via a slight modification of a reported method. ${ }^{28}$ Briefly, $14.12 \mathrm{~g}$ of Pluronic P123 and $22.6 \mathrm{~g}$ of concentrated $\mathrm{HCl}$ were dissolved in $498 \mathrm{~mL}$ of deionized water in a polypropylene bottle, and $14.12 \mathrm{~g}$ of 1-butanol was added to the solution with vigorous stirring at $35{ }^{\circ} \mathrm{C}$. After $1 \mathrm{~h}, 30.36 \mathrm{~g}$ of TEOS was added to the solution, and then, the solution was stirred at this temperature for $24 \mathrm{~h}$. The capped bottle was stored at the designated temperature of $35{ }^{\circ} \mathrm{C}$ (KIT-6-35C) or $100{ }^{\circ} \mathrm{C}$ (KIT-6-100C) for another $24 \mathrm{~h}$. The solid was filtered and dried at $100^{\circ} \mathrm{C}$ overnight, and then, the surfactant was extracted from the solid in an ethanol solution containing $\mathrm{HCl}$ (5 vol\%). KIT-6 powder was finally obtained after calcination at $550{ }^{\circ} \mathrm{C}$ for $6 \mathrm{~h}$.

\section{Synthesis of mesoporous lanthanum hydroxide}

MLHO was prepared by the hard-template approach using KIT6 , as described originally by Taguchi and Schüth. ${ }^{29}$ In a typical synthesis, $2 \mathrm{mmol}$ of $\mathrm{La}\left(\mathrm{NO}_{3}\right)_{3} \cdot 6 \mathrm{H}_{2} \mathrm{O}$ and an equimolar amount of citric acid were dissolved in $2 \mathrm{~mL}$ of anhydrous ethanol. The solution was added dropwise to $1 \mathrm{~g}$ of KIT-6, and the slurry was mixed thoroughly until ethanol was evaporated. The mixed powder was dried at $80{ }^{\circ} \mathrm{C}$ for $6 \mathrm{~h}$, and then, calcination was performed at $500{ }^{\circ} \mathrm{C}$ for $4 \mathrm{~h}$. Additional ethanol solution containing $\mathrm{La}\left(\mathrm{NO}_{3}\right)_{3} \cdot 6 \mathrm{H}_{2} \mathrm{O}$ and an equimolar amount of citric acid was infiltrated into the prefilled powder, and then, calcination was performed at $750{ }^{\circ} \mathrm{C}$ for $6 \mathrm{~h}$. The silica template was removed with $3 \mathrm{M}$ aqueous $\mathrm{NaOH}$ solution at $80{ }^{\circ} \mathrm{C}$ for $24 \mathrm{~h}$. The sample was collected after several washing steps with water and ethanol and then dried at $80{ }^{\circ} \mathrm{C}$. We prepared a series of samples using two KIT- 6 templates and different amounts of La precursor. They were named as MLHO- $X$ - $Y$, where $X$ represents the template synthesized at the designated hydrothermal temperature (KIT-6- $X$ ) and $Y$, the amount of reacted La precursor for $1 \mathrm{~g}$ of template. For instance, MLHO-35C-3 and MLHO-35C-4 were synthesized from $3 \mathrm{mmol}$ and $4 \mathrm{mmol}$ of $\mathrm{La}\left(\mathrm{NO}_{3}\right)_{3} \cdot 6 \mathrm{H}_{2} \mathrm{O}$, respectively, using the KIT-6-35C template. MLHO-35C-2 and MLHO-100C-2 were synthesized with only a single calcination step at $750{ }^{\circ} \mathrm{C}$ for $6 \mathrm{~h}$.

\section{Characterization}

The morphology of the materials was characterized by transmission electron microscopy (TEM; JEM-2011, JEOL) with an Oxford X-Max ${ }^{\mathrm{N}}-80 \mathrm{~T}$ detector for energy-dispersive X-ray spectroscopy analysis. The phase and structural parameters were characterized by X-ray diffraction (XRD) patterns using 
a PANalytical X'pert-Pro ( $\mathrm{Cu} \mathrm{K} \alpha$ radiation, $\lambda=0.15406 \mathrm{~nm}$ ). Xray photoelectron spectroscopy (XPS) was performed using Thermo Scientific K-Alpha with $\mathrm{Al} \mathrm{K} \alpha$ radiation as the X-ray source. The Brunauer-Emmett-Teller (BET) surface area and pore size distribution were determined using a Tristar 2 (Micromeritics Inc.) through nitrogen adsorption/desorption experiments.

\section{Phosphate adsorption experiments}

Batch adsorption and continuous fixed-bed column experiments were conducted to investigate the phosphate adsorption properties of the prepared samples, as outlined below.

Equilibrium adsorption experiments. Around $0.01 \mathrm{~g}$ of each sample was added to a conical tube containing a phosphate solution $(40 \mathrm{~mL})$ with a prescribed phosphate concentration (2$50 \mathrm{mg} \mathrm{P} / \mathrm{L}$ ) without $\mathrm{pH}$ adjustment. The suspensions were shaken at $28{ }^{\circ} \mathrm{C}$ for $24 \mathrm{~h}$ at $300 \mathrm{rpm}$. They were then filtered through using $0.45 \mu \mathrm{m}$ syringe filters, and the phosphate concentrations in the filtrates were analysed using the molybdenum-blue ascorbic acid method. ${ }^{30}$ The equilibrium adsorption amount of phosphate, $q_{\mathrm{e}}$, was calculated as follows:

$$
q_{\mathrm{e}}=\frac{V\left(C_{0}-C_{\mathrm{e}}\right)}{m}
$$

where $C_{0}$ and $C_{\mathrm{e}}$ are the initial and equilibrium concentrations of liquid-phase phosphate $\left(\mathrm{mg} \mathrm{L^{-1 }}\right)$, respectively; $V$ is the volume of phosphate solution (L), and $m$ is the sorbent mass (g).

The isotherm data were fitted to the Langmuir and Freundlich isotherm models given by eqn (2) and (3), respectively:

Langmuir model:

$$
q_{\mathrm{e}}=q_{\mathrm{m}} \frac{K_{\mathrm{L}} C_{\mathrm{e}}}{1+K_{\mathrm{L}} C_{\mathrm{e}}}
$$

Freundlich model:

$$
q_{\mathrm{e}}=K_{\mathrm{F}} C_{\mathrm{e}}^{1 / n}
$$

where $q_{\mathrm{m}}$ is the maximum adsorption capacity of adsorbent (mg $\left.\mathrm{g}^{-1}\right), K_{\mathrm{L}}$ is the Langmuir adsorption constant, and $K_{\mathrm{F}}$ and $n$ are the Freundlich constants.

Phosphate adsorption kinetics and low-concentration phosphate removal. To assess the adsorption kinetics, phosphate solutions of different concentrations ( 5 and $10 \mathrm{mg} \mathrm{P} / \mathrm{L}$ ) were prepared in sets of conical tubes. The same amount of MLHO sample ( $0.01 \mathrm{~g}$ ) was added to each tube, and it was then shaken at $28{ }^{\circ} \mathrm{C}$ at $300 \mathrm{rpm}$. After each specified reaction time, a $10 \mathrm{~mL}$ aliquot was taken from the tube and filtered for determining the phosphate concentration. To analyse the adsorption process, the experimental data were fitted to the following pseudo-first order and pseudo-second order models:

Pseudo-first order model:

$$
q_{t}=q_{\mathrm{e}}\left(1-\mathrm{e}^{-k_{1} t}\right)
$$

Pseudo-second order model:

$$
\frac{t}{q_{t}}=\frac{1}{k_{2} q_{\mathrm{e}}^{2}}+\frac{t}{q_{\mathrm{e}}}
$$

where $t$ is the adsorption time $(\mathrm{min}) ; q_{t}$ and $q_{\mathrm{e}}$ are the amount of phosphate adsorbed at a given time $\left(\mathrm{mg} \mathrm{g}^{-1}\right)$ and at equilibrium $\left(\mathrm{mg} \mathrm{g}^{-1}\right)$, respectively; and $k_{1}$ and $k_{2}$ are the pseudo-first order and pseudo-second order adsorption rate constants, respectively.

Phosphate removal experiments with low initial $\mathrm{P}$ concentration were conducted using a $2 \mathrm{mg} \mathrm{P} / \mathrm{L}$ solution; the experimental method was the same as described above.

Column flow-through adsorption experiments. Adsorption in a fixed-bed column was performed in a polypropylene column (diameter: $12.8 \mathrm{~mm}$, height: $60 \mathrm{~mm}$ ) packed with $3.4 \mathrm{~mL}$ ( $\sim 1 \mathrm{~g})$ of MLHO-100C-2 sample. The $2 \mathrm{mg}$ P/L solution was flowed through the fixed-bed column at a flow rate of 0.56 $\mathrm{mL} \min ^{-1}$. The corresponding empty bed contact time (EBCT) was $\sim 6 \mathrm{~min}$ and the breakthrough point was set as $0.2 \mathrm{mg} \mathrm{P} / \mathrm{L}$ according to the effluent discharge standard of WWTPs in Korea.

\section{Results and discussion}

\section{Characterization of materials}

MLHO samples were synthesized by the hard-template method using KIT- 6 as the template to prepare an ordered structure with nanometer-sized pores. Two sets of KIT- 6 were prepared at two temperatures, $35{ }^{\circ} \mathrm{C}$ (KIT-6-35C) and $100{ }^{\circ} \mathrm{C}$ (KIT-6-100C), to alter the pore structure. Table $\mathrm{S} 1 \dagger$ lists the structural characteristics of the KIT- 6 templates (e.g., BET specific surface area $\left(S_{\text {BET }}\right)$, pore diameter $\left(d_{\text {pore }}\right)$, and total pore volume $\left.\left(V_{\mathrm{t}}\right)\right)$; further, Fig. S1 $\uparrow$ shows TEM images and $\mathrm{N}_{2}$ sorption isotherms. A previous study ${ }^{31}$ showed that a lower aging temperature of KIT- 6 resulted in a smaller pore volume and pore size with poor interconnectivity among channel systems; similarly, our study showed that KIT-6-100C had larger surface area, pore size, and total pore volume than KIT-6-35C.

Incipient wetness impregnation of the La precursor inside the pores of each template was performed, following which the citrate sol-gel process was performed. ${ }^{32}$ After calcination, the silica template was removed via etching with $\mathrm{NaOH}$. By varying the amount of loaded precursor, a series of MLHOs were synthesized. Fig. 1 shows XRD patterns of synthesized MLHOs. Most MLHOs had a mixture phase of amorphous oxide and crystalline $\mathrm{La}(\mathrm{OH})_{3}$ with well-resolved peaks. $\mathrm{La}_{2} \mathrm{O}_{3}$ is hygroscopic in nature and quickly converts into $\mathrm{La}(\mathrm{OH})_{3}$ in a moist atmosphere. Before the etching process, XRD analysis was used to confirm that the composites contained the $\mathrm{La}_{2} \mathrm{O}_{3}$ phase (Fig. S2 $\dagger$ ). Prolonged reaction ( $24 \mathrm{~h}$ ) with aqueous $\mathrm{NaOH}$ solution in the etching process resulted in transformation into $\mathrm{La}(\mathrm{OH})_{3}$. Further, the XRD patterns of MLHO samples prepared using a small amount of La precursor $\left(2 \mathrm{mmol} \mathrm{g}^{-1}\right)$ revealed a largely amorphous structure without distinct crystalline peaks.

The morphologies of the synthesized MLHOs were characterized by TEM. The MLHO samples had well-defined pore structures within the nanometer size range (Fig. 2 and $\mathrm{S} 3 \dagger$ ). In 


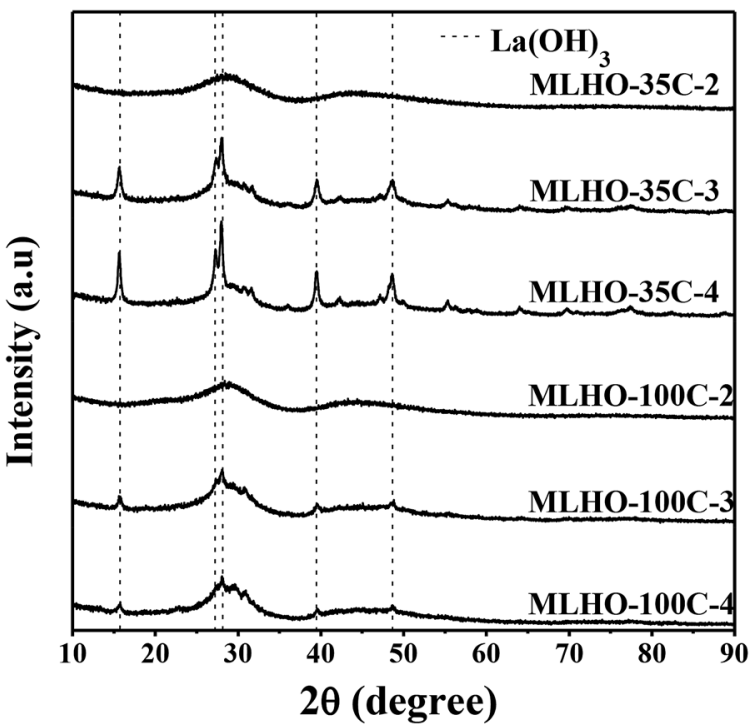

Fig. 1 X-ray diffraction (XRD) patterns of the synthesized mesoporous lanthanum hydroxides (MLHOs). Dashed lines represent the reference XRD pattern of $\mathrm{La}(\mathrm{OH})_{3}$ (JCPDS\#31-1481).

particular, MLHOs prepared with high loading of La precursors ( 3 or $4 \mathrm{mmol} \mathrm{g}^{-1}$ ) had organized pore and wall structures comprising arrays of nanoparticles. This ordered mesopore structure was expected given the use of KIT- 6 as the mold. As expected from the XRD results, MLHO-35C-2 and MLHO-100C-2 showed relatively imperfect development of ordered structures. Further, STEM images with elemental mapping showed the presence of silicon within the wall even after long-term etching (72 h) using $3 \mathrm{M} \mathrm{NaOH}$ (Fig. S3d $\dagger$ ). The calcination of La precursor with silica at high temperatures $\left(>850{ }^{\circ} \mathrm{C}\right)$ has been reported to yield a lanthanum silicate phase. ${ }^{33,34}$ In this study, we calcinated samples at a lower temperature $\left(750{ }^{\circ} \mathrm{C}\right)$ to avoid the formation of a lanthanum silicate phase. However, some lanthanum silicate phase was evidently formed, and it resisted etching. This lanthanum silicate became amorphous under relatively low-temperature and short-duration calcination, resulting in less-distinguishable XRD patterns.
XPS analysis was conducted to evaluate the surface composition and valence state of materials (Fig. 3 and S4 $\dagger$ ). Highresolution spectra around the binding energy of the La $4 \mathrm{~d}$ region (Fig. 3a and $\mathrm{S} 4 \mathrm{a} \dagger$ ) revealed the existence of $\mathrm{La}$ (III) with binding energies at $102.4 \mathrm{eV}\left(4 \mathrm{~d}_{5 / 2}\right)$ and $105.6 \mathrm{eV}\left(4 \mathrm{~d}_{3 / 2}\right)$. The profiles in the La $3 d$ region showed split peaks of $\mathrm{La} 3 \mathrm{~d}_{3 / 2}$ and La $3 \mathrm{~d}_{5 / 2}$ as multiplet splitting, representing the state of $\mathrm{La}$ (III) (Fig. $3 \mathrm{~b}$ and $\mathrm{S} 4 \mathrm{~b} \dagger$ ). ${ }^{35}$ In particular, the splitting in La $3 \mathrm{~d}_{5 / 2}$ was found to be $\mathrm{DE}=\sim 3.7 \mathrm{eV}$; this is characteristic of $\mathrm{La}(\mathrm{OH})_{3} \cdot{ }^{36} \mathrm{In}$ addition to the XPS profiles in the $\mathrm{La} 4 \mathrm{~d}$ and $\mathrm{La} 3 \mathrm{~d}$ regions, peaks in the La $4 \mathrm{p}$ region were examined to determine the state of La (Fig. 3c and S4c $\dagger$ ). The main peak of $4 p_{3 / 2}$ was at $196.1 \mathrm{eV}$. The position of the satellite peak and its intensity can be used to distinguish $\mathrm{La}_{2} \mathrm{O}_{3}$ and $\mathrm{La}(\mathrm{OH})_{3}$. The satellite peak represented $\mathrm{La}(\mathrm{OH})_{3}$ because its relative position to the main peak was $\sim 3.6 \mathrm{eV}$ with low intensity. ${ }^{35,36}$ Overall, XPS analysis confirmed that the surface of MLHOs did not contain $\mathrm{La}_{2} \mathrm{O}_{3}$; instead, they contained $\mathrm{La}(\mathrm{OH})_{3}$. From the XRD and TEM results, we concluded that MLHOs had a stable surface of crystalline $\mathrm{La}(\mathrm{OH})_{3}$ on a less crystalline backbone of $\mathrm{La}_{2} \mathrm{O}_{3}$ /lanthanum silicate after aqueous-phase etching.

The pore structure was characterized by $\mathrm{N}_{2}$ adsorption/ desorption isotherms. The surface area of MLHOs showed higher dependency based on the amount of La precursor used (Table 1). Smaller amounts of precursor resulted in larger BET surface area $\left(S_{\mathrm{BET}}\right)$ of MLHOs from both KIT-6-35C and KIT-6100C. In particular, MLHO-35C-2 and MLHO-100C-2 had large surface area of 429.8 and $348.3 \mathrm{~m}^{2} \mathrm{~g}^{-1}$, respectively; these areas were much larger than those of the bulk counterpart, ${ }^{9,37}$ nanosized particles, ${ }^{20}$ and hierarchical microparticles. ${ }^{22}$ Further, the pore structure was affected by both the template and the amount of precursor used. Fig. 4 and $\mathrm{S} 5 \dagger$ show the $\mathrm{N}_{2}$ adsorption/desorption isotherms and calculated pore distributions of the MLHOs. Most MLHOs exhibited a bimodal distribution as a characteristic structure of replicated materials from KIT-6 aged at low temperatures. The first peak was at $4-5 \mathrm{~nm}$, in agreement with the wall thickness of KIT-6 (KIT-6-35C: $4.4 \mathrm{~nm}$; KIT-6-100C: $4.7 \mathrm{~nm}$ ) as characterized by TEM (Fig. S1 $\dagger$ ). As mentioned previously, KIT- 6 has two sets of mesopore channels, and the size and interconnectivity among channels
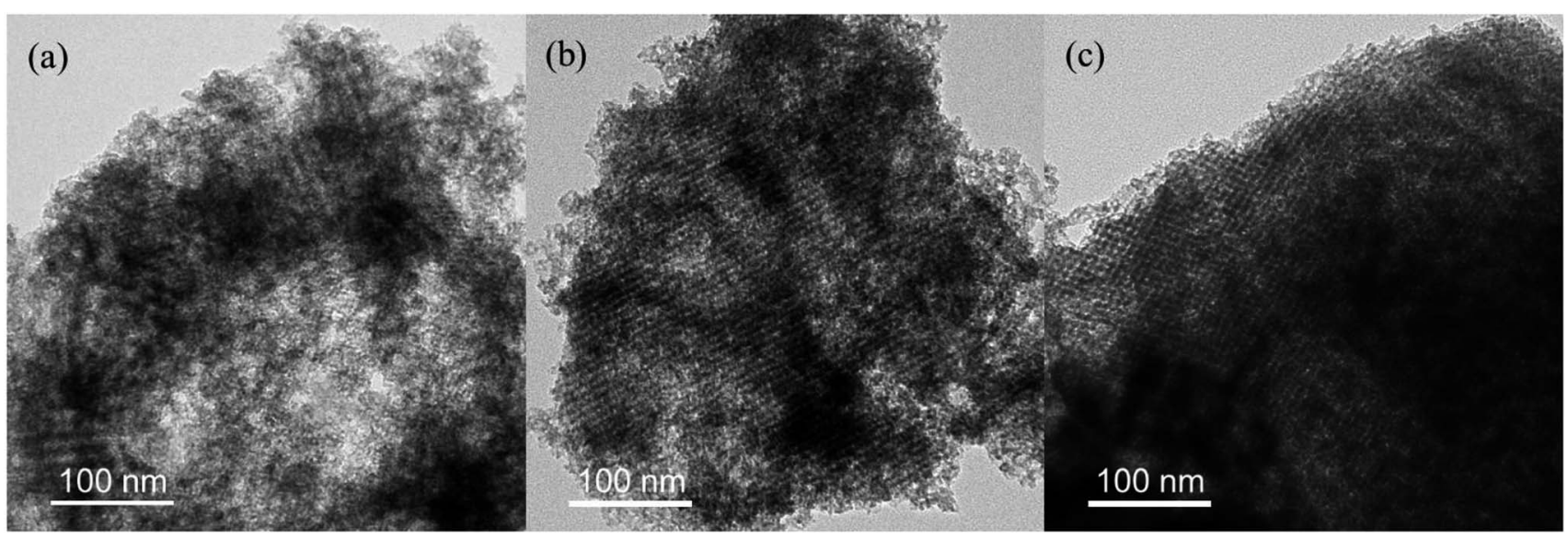

Fig. 2 Transmission electron microscopy images of MLHO-100Cs: (a) MLHO-100C-2, (b) MLHO-100C-3, and (c) MLHO-100C-4. 

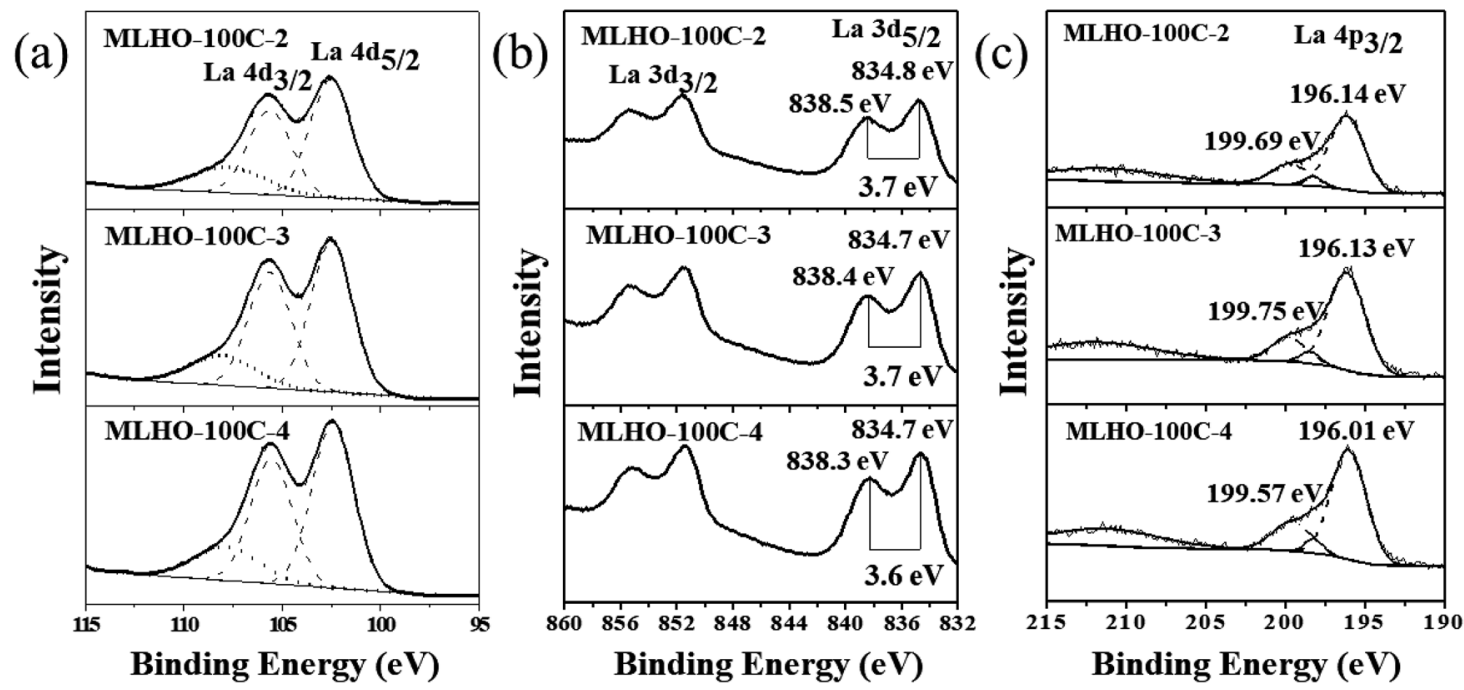

Fig. 3 X-ray photoelectron spectroscopy spectra of MLHO-100Cs: (a) La 4d region, (b) La 3d region, and (c) La 4p region.

Table 1 Structural characteristics and maximum adsorption capacity (at $28{ }^{\circ} \mathrm{C}$ ) of the synthesized mesoporous lanthanum hydroxides (MLHOs)

\begin{tabular}{llllc}
\hline Sample & $S_{\text {BET }}\left(\mathrm{m}^{2} \mathrm{~g}^{-1}\right)$ & $d^{a}(\mathrm{~nm})$ & $V_{\mathrm{t}}\left(\mathrm{cm}^{3} \mathrm{~g}^{-1}\right)$ & $q_{\mathrm{m}}\left(\mathrm{mg} \mathrm{g}^{-1}\right)$ \\
\hline MLHO-100C-2 & 348.3 & $5.6 / 9.9$ & 1.05 & 109.41 \\
MLHO-100C-3 & 241.7 & $5.2 / 9.5$ & 0.74 & 93.90 \\
MLHO-100C-4 & 221.3 & $4.2 / 8.9$ & 0.62 & 90.91 \\
MLHO-35C-2 & 429.8 & $5.0 / 8.2$ & 0.76 & 98.62 \\
MLHO-35C-3 & 263.1 & $5.3 / 9.1$ & 0.57 & 80.32 \\
MLHO-35C-4 & 150.4 & $3.9 / 7.6$ & 0.44 & 76.10
\end{tabular}

${ }^{a}$ Pore diameter, $d$, was calculated from the $\mathrm{N}_{2}$ desorption isotherm by the Barrett-Joyner-Halenda (BJH) method. $S_{\mathrm{BET}}, V_{\mathrm{t}}$, and $q_{\mathrm{m}}$ are the BET surface area, total pore volume, and maximum adsorption capacity by Langmuir model, respectively.

depend on the hydrothermal treatment temperature. KIT- 6 treated hydrothermally at low temperature $\left(<100{ }^{\circ} \mathrm{C}\right)$ showed less development of micropores among mesopore channels, resulting in poor infiltration of the La precursor. This explained why MLHOs had pores of 8-10 $\mathrm{nm}$ size; this is equivalent to the dimension of two walls and a pore of KIT-6..$^{38,39}$ Thus, the MLHOs from KIT-6-35C had a more distinct bimodal pore distribution relative to those from KIT-6-100C owing to less filling of La precursor into the mesopores in the KIT-6-35C matrix. Interestingly, the isotherms of MLHO-100Cs showed a hysteresis loop at a high relative pressure $\left(P / P^{0}>0.9\right)$, suggesting the presence of macroporosity. Pore size distribution analysis (Fig. 4d) also confirmed that MLHO-100Cs had irregular pores of 15-50 nm size. The presence of large pores accounts for the large pore volume of MLHO-100Cs as well as their relatively smaller surface area compared to those of MLHO-35Cs. Overall, both the structure characteristics of templates and the amount of La precursor induced the variation of growth of $\mathrm{La}(\mathrm{OH})_{3}$ in mesopore channels of templates, and this affected the pore structure of the resulting MLHOs.

\section{Adsorption of phosphate by MLHOs}

Phosphate adsorption equilibrium. The MLHOs had large surface areas and long channels of nanosized pores; therefore, they showed potential as efficient adsorbents and reaction vessels. The phosphate adsorption performance of the MLHOs was investigated via a series of batch tests. Fig. 5 shows phosphate adsorption isotherms of the MLHO-100Cs at $28{ }^{\circ} \mathrm{C}$, where $q_{\mathrm{e}}$ increased sharply at low $C_{\mathrm{e}}$ values of up to $\sim 0.6 \mathrm{mg} \mathrm{P} / \mathrm{L}$ but plateaued at higher $C_{\mathrm{e}}$ values (see adsorption isotherms of the MLHO-35Cs in Fig. S6†). Langmuir and Freundlich models were used to fit the isotherm data; Table $\mathrm{S} 2 \uparrow$ lists the estimated adsorption constants obtained from the isotherms. As indicated by the correlation coefficients $\left(R^{2}\right)$, the isotherm data showed much better fit to the Langmuir model (see Fig. S7 $\dagger$ ). This indicated that monolayer adsorption occurred at the homogenous surface of $\mathrm{La}(\mathrm{OH})_{3}$, as found in previous reports of other lanthanum-based adsorbents. ${ }^{5,12}$ Table 1 shows that MLHO100C-2 had the highest maximum capacity of $109.41 \mathrm{mg} \mathrm{P} \mathrm{g}^{-1}$ at $28{ }^{\circ} \mathrm{C}\left(q_{\mathrm{m}}\right.$ by the Langmuir model) among the MLHOs; this value was larger than those of reported La-doped adsorbents (see summary in Table S3†).

Within the same KIT-6 set, MLHOs with large surface areas had high adsorption capacities. Further, MLHO-100Cs from KIT-6-100C had larger adsorption capacity but smaller surface area than MLHO-35Cs from KIT-6-35C. These results indicate that, in addition to surface area, the pore structure is also an important parameter of adsorbents. As shown in Fig. 4d, MLHO-100Cs had large pores of 15-50 $\mathrm{nm}$ size along with large pore volume; these could result in efficient contact with phosphate during the adsorption process and promote the transformation into lanthanum phosphate. This result agrees with previous studies on La-doped adsorbents indicating that support materials with macropores had high adsorption capacity owing to the enhanced accessibility of phosphate to La. ${ }^{\mathbf{4 0 , 4 1}}$ Our results indicate that when designing phosphate adsorbents, both the surface area and the pore structure should 
(a)

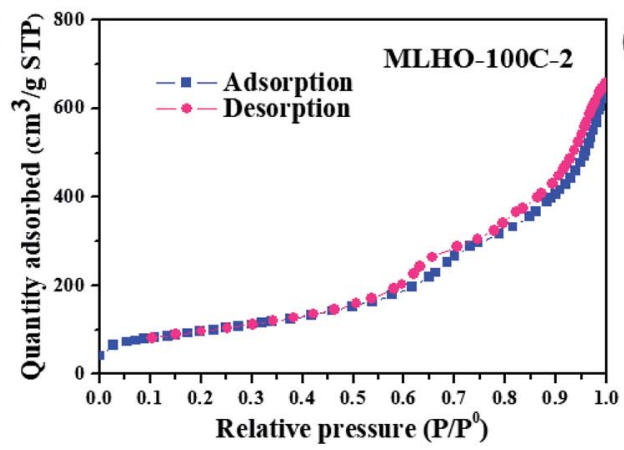

(c)

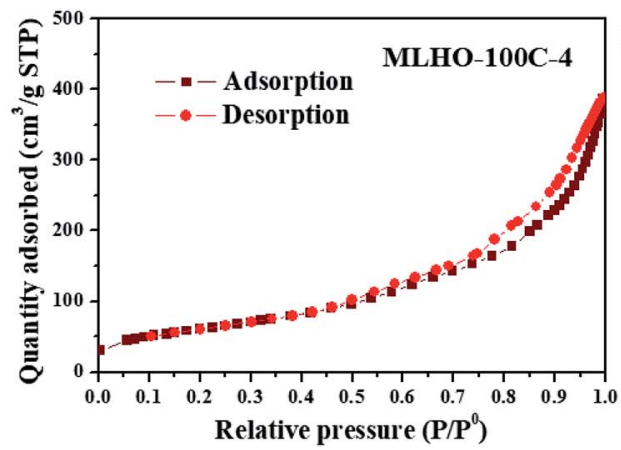

(b)

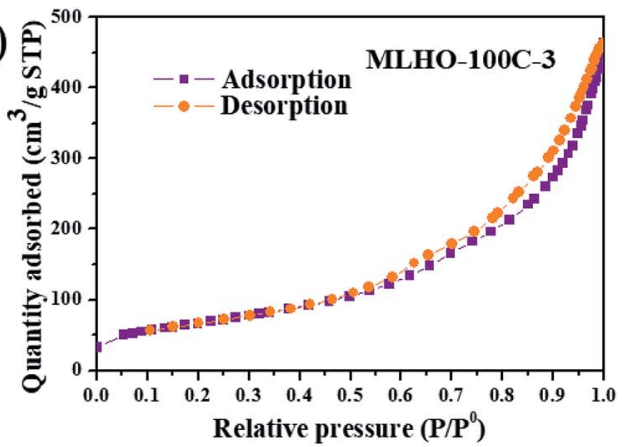

(d)

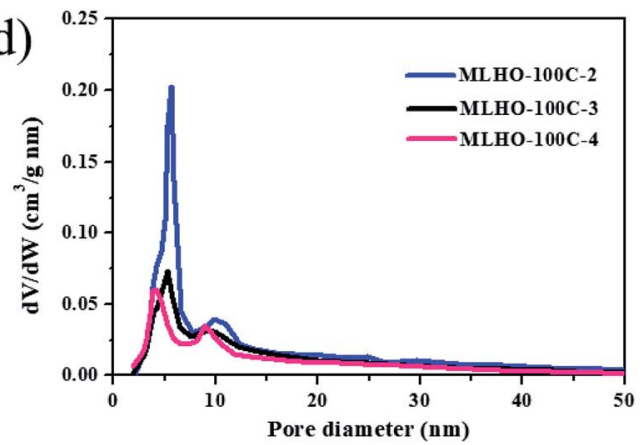

Fig. $4 \mathrm{~N}_{2}$ adsorption/desorption isotherms of (a) MLHO-100C-2, (b) MLHO-100C-3, and (c) MLHO-100C-4. (d) Pore size distributions of $\mathrm{MLHO}-100 \mathrm{Cs}$ as calculated by the Barrett-Joyner-Halenda $(\mathrm{BJH})$ method.

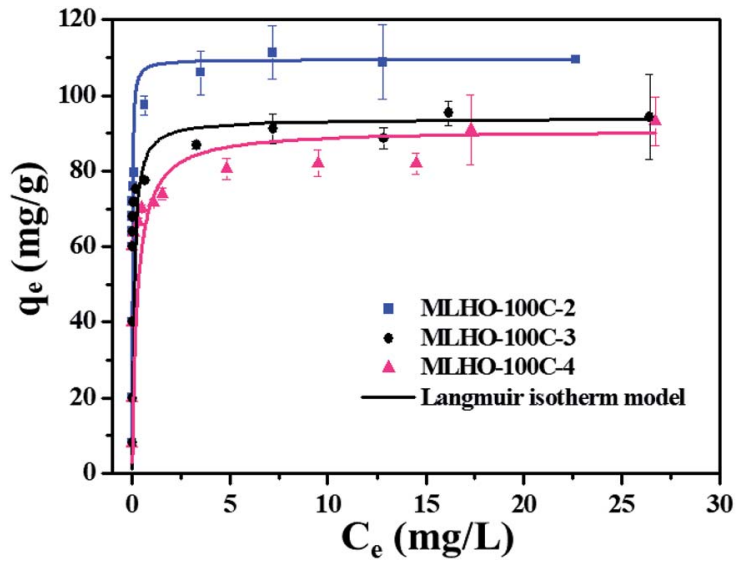

Fig. 5 Adsorption isotherms of phosphate on MLHO-100Cs. Solid lines represent plots fitted to Langmuir isotherm model.

be considered in terms of the balance between mesopores and macropores.

Based on these findings, we selected MLHO-100C-2, with the highest adsorption capacity, for further investigating the phosphate adsorption performance.

Adsorption kinetics. Fig. 6 and Table $\mathrm{S} 4 \dagger$ show the results of the adsorption kinetic study using MLHO-100C-2. The dynamic behaviour of phosphate adsorption by the MLHO adsorbent at two initial concentrations of 5 and $10 \mathrm{mg} \mathrm{P} / \mathrm{L}$ was satisfactorily described by the pseudo-second-order kinetic model $\left(R^{2}=\right.$ 0.999), indicating that phosphate likely adsorbed onto the MLHO adsorbent via chemisorption.
The kinetic study revealed that the MLHO adsorbent achieved very fast phosphate removal. Phosphate adsorption by MLHO adsorbent reached equilibrium within $30 \mathrm{~min}$ and $2 \mathrm{~h}$ at initial concentrations of 5 and $10 \mathrm{mg} \mathrm{P} / \mathrm{L}$, respectively. Accordingly, the adsorption rate constant, $k_{2}$, in solutions of 5 and $10 \mathrm{mg} \mathrm{P} / \mathrm{L}$ was calculated to be 0.106 and $0.006 \mathrm{~g} \mathrm{mg}^{-1} \mathrm{~min}^{-1}$, respectively; these values were higher than those of previously reported Labased nanostructures. ${ }^{41}$ The calculated $k_{2}$ for the solution with initial concentration of $5 \mathrm{mg} \mathrm{P} / \mathrm{L}$ was approximately two orders of magnitude greater than that for the solution with initial concentration of $10 \mathrm{mg} \mathrm{P} / \mathrm{L}$. This result shows that phosphate removal occurs more rapidly at lower concentrations.

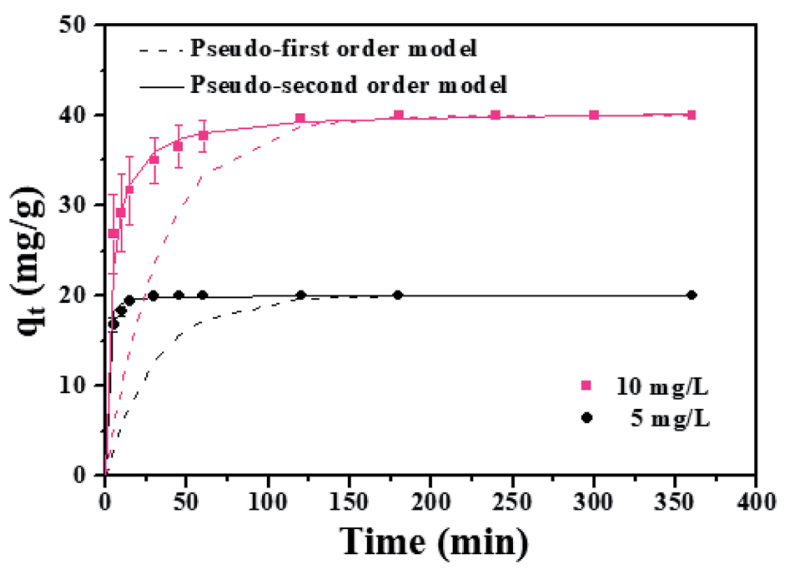

Fig. 6 Adsorption kinetics of MLHO-100C-2. Initial phosphate concentrations were 5 and $10 \mathrm{mg} \mathrm{P} / \mathrm{L}$ and dosage of MLHO-100C-2 was $0.25 \mathrm{~g} \mathrm{~L}^{-1}$. 
Adsorption behaviour at low phosphate concentration. WWTPs can effectively treat phosphate to yield effluent that meets current $\mathrm{P}$ standards of $<2 \mathrm{mg} \mathrm{P} / \mathrm{L}$; however, direct discharge into natural water bodies could still cause eutrophication. ${ }^{40}$ Because of the rising demand for clean water with extremely low levels of $\mathrm{P}$ and increasingly strict regulations on the total $\mathrm{P}$ discharge, the phosphate removal performance of MLHOs at low initial $\mathrm{P}$ concentrations should be studied further. Toward this end, adsorption by MLHO-100C-2 was investigated in a synthetic solution with an initial concentration of $2 \mathrm{mg} \mathrm{P} / \mathrm{L}$.

The MLHO adsorbent exhibited very fast adsorption, with $86.3 \%$ and $99.5 \%$ of phosphate in the initial solution removed within just 1 and $5 \mathrm{~min}$, respectively (Fig. 7). After $10 \mathrm{~min}$, $99.8 \%$ of phosphate was removed and the $\mathrm{P}$ concentration of the solution dramatically decreased to $4 \mu \mathrm{g} \mathrm{P} / \mathrm{L}$. After adsorption, the residual $\mathrm{P}$ concentration of the solution was much smaller than the maximum allowable concentration for urban WWTPS in countries such as the United Kingdom $(1 \mathrm{mg} \mathrm{P} / \mathrm{L}),{ }^{42}$ Korea $(0.2 \mathrm{mg} \mathrm{P} / \mathrm{L}),{ }^{43}$ and South America $(0.02 \mathrm{mg} \mathrm{P} / \mathrm{L}) .{ }^{44}$ These results indicate that MLHO is an excellent candidate for phosphate removal via high-speed adsorption to achieve levels low enough to prevent eutrophication.

Continuous column experiments. The phosphate removal process in WWTPs is mostly based on continuous adsorption. To further evaluate the potential of MLHOs in practical applications, phosphate removal by MLHO-100C- 2 was conducted in a continuous fixed-bed column by feeding a solution of $2 \mathrm{mg} \mathrm{P} / \mathrm{L}$ to simulate secondary effluents of urban WWTPs. The adsorption profile revealed outstanding $\mathrm{P}$ adsorption performance in the continuous application (Fig. S8†). Based on the maximum allowable total $\mathrm{P}$ in effluents of WWTPs in Korea $(0.2 \mathrm{mg} \mathrm{P} / \mathrm{L})$, the effective treatment volume of MLHO-100C-2 for phosphate uptake was $\sim 4900$ bed volumes (BV). The treatment capacity corresponds to $\sim 16700 \mathrm{~kg}$ wastewater per $\mathrm{kg}$ MLHO. MLHOs showed superior performance comparing to La-doped adsorbents. ${ }^{5,16,45}$ This indicates the great potential of MLHOs for long-term treatment of wastewater containing low phosphate concentrations.

MLHOs showed more effective phosphate removal in both batch and continuous fixed-bed column experiments than

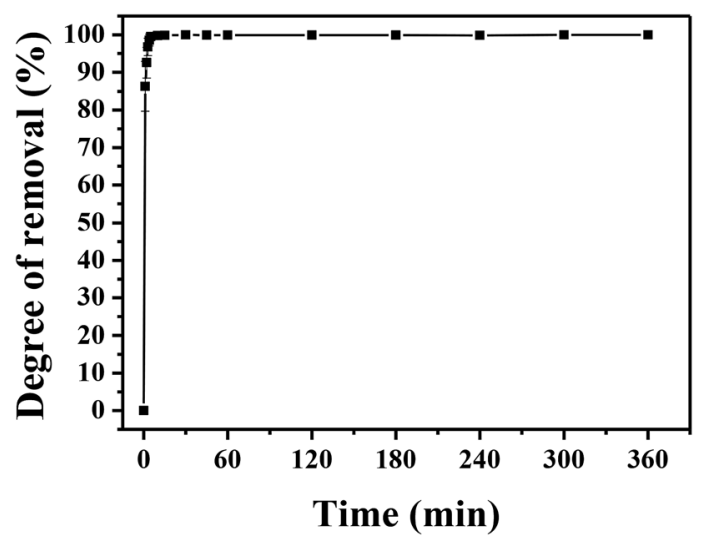

Fig. 7 Phosphate removal by MLHO-100C-2 at initial P concentration of $2 \mathrm{mg} \mathrm{P} / \mathrm{L}$. previously reported La-doped adsorbents. Further, they showed rapid and complete removal of low phosphate concentrations as well as promising long-term treatment ability. This outstanding performance of MLHOs for phosphate adsorption resulted from the chemically controlled and rigid surface of $\mathrm{La}(\mathrm{OH})_{3}$ as well as the optimized porosity in the nanometer regime for enabling enhanced accessibility to phosphate. This result implies that mesoporous adsorbents comprising active materials could show better performance than doped or host/guest platforms for the removal of other adsorbates.

\section{Conclusions}

MLHOs were fabricated by the hard-template method. This enabled the control of their microstructures by adjusting reaction conditions including the template and amount of La precursor. The synthesized MLHO adsorbent showed great potential for phosphate removal from solutions containing various $\mathrm{P}$ concentrations owing to their nanosized pores and $\mathrm{La}(\mathrm{OH})_{3}$ composition. The surface area of the MLHOs was closely related to their phosphate removal capacity as this process was governed by monolayer adsorption of phosphate on the MLHO surface. Further, it was important for the adsorbent to have a proper pore structure. Accordingly, MLHO-100C-2 synthesized using KIT- 6 aged at $100{ }^{\circ} \mathrm{C}$ with $2 \mathrm{mmol} \mathrm{g}^{-1}$ of La precursor exhibited the highest adsorption capacity. It also showed rapid adsorption of phosphate in a $2 \mathrm{mg} \mathrm{P} / \mathrm{L}$ solution, which is a common standard for WWTP effluents. Most phosphate was removed within $10 \mathrm{~min}$, after which the $\mathrm{P}$ concentration in the solution dramatically decreased to $4 \mu \mathrm{g} \mathrm{P} / \mathrm{L}$. In conclusion, MLHO is an excellent adsorbent for phosphate removal from solutions containing both high and low $\mathrm{P}$ concentrations, and it can be used in WWTPs to meet increasingly stringent discharge standards.

\section{Conflicts of interest}

There are no conflicts to declare.

\section{Acknowledgements}

This research was supported by C1 Gas Refinery Program through the National Research Foundation of Korea (NRF) funded by the Ministry of Science and ICT (2015M3D3A1A01064908) and also supported by the National Research Foundation of Korea (NRF) grant funded by the Korea government (MEST) (2018R1A2B6001415).

\section{Notes and references}

1 K. G. Sellner, G. J. Doucette and G. J. Kirkpatrick, J. Ind. Microbiol. Biotechnol., 2003, 30, 383-406.

2 European Commission, Guidance document on eutrophication assessment in the context of European water policies, Office for Official Publications of the European Communities, Luxembourg, 2009. 
3 G. K. Morse, S. W. Brett, J. A. Guy and J. N. Lester, Sci. Total Environ., 1998, 212, 69-81.

4 Commission Implementing Decision (EU) 2018/1147 of 10 August 2018 establishing best available techniques (BAT) conclusions for waste treatment, under Directive 2010/75/EU of the European Parliament and of the Council, Official Journal of the European Union, 2018, vol. L208, pp. 38-90.

5 Y. Wu, X. Li, Q. Yang, D. Wang, Q. Xu, F. Yao, F. Chen, Z. Tao and X. Huang, J. Environ. Manage., 2019, 231, 370-379.

6 E. Rott, H. Steinmetz and J. W. Metzger, Sci. Total Environ., 2018, 615, 1176-1191.

7 X. Luo, X. Wang, S. Bao, X. Liu, W. Zhang and T. Fang, Sci. Rep., 2016, 6, 39108.

8 H.-S. Yoon, K. W. Chung, C.-J. Kim, J.-H. Kim, H.-S. Lee, S.-J. Kim, S.-I. Lee, S.-J. Yoo and B.-C. Lim, Korean J. Chem. Eng., 2018, 35, 470-478.

9 J. Xie, Z. Wang, S. Lu, D. Wu, Z. Zhang and H. Kong, Chem. Eng. J., 2014, 254, 163-170.

10 P. Huang, Y. Zhao, J. Zhang, Y. Zhu and Y. Sun, Nanoscale, 2013, 5, 10844-10848.

11 W. Huang, Y. Zhang and D. Li, J. Environ. Manage., 2017, 193, 470-482.

12 W. Huang, X. Yu, J. Tang, Y. Zhu, Y. Zhang and D. Li, Microporous Mesoporous Mater., 2015, 217, 225-232.

13 J. Xie, Z. Wang, D. Fang, C. Li and D. Wu, J. Colloid Interface Sci., 2014, 423, 13-19.

14 E. W. Shin, K. G. Karthikeyan and M. A. Tshabalala, Environ. Sci. Technol., 2005, 39, 6273-6279.

15 J. He, W. Wang, F. Sun, W. Shi, D. Qi, K. Wang, R. Shi, F. Cui, C. Wang and X. Chen, ACS Nano, 2015, 9, 9292-9302.

16 S. Dong, Y. Wang, Y. Zhao, X. Zhou and H. Zheng, Water Res., 2017, 126, 433-441.

17 W.-Y. Huang, D. Li, Z.-Q. Liu, Q. Tao, Y. Zhu, J. Yang and Y.-M. Zhang, Chem. Eng. J., 2014, 236, 191-201.

18 L. Zhang, Q. Zhou, J. Liu, N. Chang, L. Wan and J. Chen, Chem. Eng. J., 2012, 185-186, 160-167.

19 S. K. Zheng, J. J. Chen, X. M. Jiang and X. F. Li, Chem. Eng. J., 2011, 169, 194-199.

20 L. Fang, B. Wu, J. K. M. Chan and I. M. C. Lo, Chemosphere, 2018, 192, 209-216.

21 T. Liu, X. Chen, X. Wang, S. Zheng and L. Yang, Chem. Eng. J., 2018, 335, 443-449.

22 J. Liu, G. Wang, L. Lu, Y. Guo and L. Yang, RSC Adv., 2017, 7, 40965-40972.

23 E. Lim, C. Jo and J. Lee, Nanoscale, 2016, 8, 7827-7833.

24 P. Bhanja and A. Bhaumik, Chem. Rec., 2019, 19, 333-346.

25 B. G. Cha and J. Kim, Wiley Interdiscip. Rev.: Nanomed. Nanobiotechnol., 2019, 11, e1515.
26 Y. Ren, Z. Ma and P. G. Bruce, Chem. Soc. Rev., 2012, 41, 4909-4927.

27 K. An, S. Alayoglu, N. Musselwhite, S. Plamthottam, G. Melaet, A. E. Lindeman and G. A. Somorjai, J. Am. Chem. Soc., 2013, 135, 16689-16696.

28 F. Kleitz, S. H. Choi and R. Ryoo, Chem. Commun., 2003, 2136-2137, DOI: 10.1039/B306504A.

29 A. Taguchi and F. Schüth, Microporous Mesoporous Mater., 2005, 77, 1-45.

30 Standard Methods for the Examination of Water and Wastewater, ed. E. W. Rice and L. Bridgewater, American Public Health Association, Washington, D.C., 22nd edn, 2012.

31 H. Tüysüz, C. W. Lehmann, H. Bongard, B. Tesche, R. Schmidt and F. Schüth, J. Am. Chem. Soc., 2008, 130, 11510-11517.

32 A. E. Danks, S. R. Hall and Z. Schnepp, Mater. Horiz., 2016, 3, 91-112.

33 R. Zhang, P. Li, N. Liu, W. Yue and B. Chen, J. Mater. Chem. A, 2014, 2, 17329-17340.

34 B. Ballinger, J. Motuzas, C. R. Miller, S. Smart and J. C. Diniz da Costa, Sci. Rep., 2015, 5, 8210.

35 D. F. Mullica, H. O. Perkins, C. K. C. Lok and V. Young, J. Electron Spectrosc. Relat. Phenom., 1993, 61, 337-355.

36 M. F. Sunding, K. Hadidi, S. Diplas, O. M. Løvvik, T. E. Norby and A. E. Gunnæs, J. Electron Spectrosc. Relat. Phenom., 2011, 184, 399-409.

37 J. Xie, Y. Lin, C. Li, D. Wu and H. Kong, Powder Technol., 2015, 269, 351-357.

38 F. Jiao, A. H. Hill, A. Harrison, A. Berko, A. V. Chadwick and P. G. Bruce, J. Am. Chem. Soc., 2008, 130, 5262-5266.

39 D. Klaus, S. Amrehn, M. Tiemann and T. Wagner, Microporous Mesoporous Mater., 2014, 188, 133-139.

40 W. Huang, Y. Zhu, J. Tang, X. Yu, X. Wang, D. Li and Y. Zhang, J. Mater. Chem. A, 2014, 2, 8839-8848.

41 J. Yang, P. Yuan, H.-Y. Chen, J. Zou, Z. Yuan and C. Yu, J. Mater. Chem., 2012, 22, 9983-9990.

42 UK legislation, The Urban Waste Water Treatment (England and Wales) Regulations 1994, UK Legislation, 1994, http:// www.legislation.gov.uk/uksi/1994/2841/contents/made.

43 Ministry of Government Legislation in Korea, Enforcement Decree of Sewerage Act, Ministry of Government Legislation, 2018, http://www.law.go.kr.

44 A. F. D. Sousa, T. P. Braga, E. C. C. Gomes, A. Valentini and E. Longhinotti, Chem. Eng. J., 2012, 210, 143-149.

45 Q. Zhang, J. Teng, G. Zou, Q. Peng, Q. Du, T. Jiao and J. Xiang, Nanoscale, 2016, 8, 7085-7093. 